\title{
A relação da língua portuguesa com a língua espanhola (peninsular e latino-americana): reflexos em livros didáticos
}

\author{
Sergio Flores Pedroso \\ Universidade Federal de Mato Grosso \\ serflope@terra.com.br
}

\section{Resumo}

Neste trabalho faz-se um rápido percurso pela história da relação da língua portuguesa com a língua espanhola, após a sua constituição como línguas oficiais de Estados nacionais, pontuando marcos cujos efeitos se estendem até a atualidade no ensino de espanhol como língua estrangeira (ELE). Visando ao público dos cursos de formação de professores -planejadores de currículos e programas, professores e formandos-, pretende-se, por meio de uma perspectiva que ressalta o funcionamento da ideologia e das relações de poder materializadas na política, apresentar subsídios para a compreensão do que influência a abordagem do espanhol como língua estrangeira em função do seu ensino e, dentro deste, o livro didático.

Palavras-chave: Linguística Aplicada. História. Espanhol Língua Estrangeira. Livro Didático. Currículo.

\begin{abstract}
This paper intends to contribute to the comprehension of historical aspects that influence Spanish as a foreign language aiming its learning and textbooks. For attaining this aim, specific moments of the history of relationship between Portuguese and Spanish languages after its constitution as official languages of national states will be commented. Power relationships and ideology materialize themselves as political practice and here this aspect is considered. The effects of this kind of relationships work nowadays on the learning of Spanish as a foreign language. The public this paper aims at is that of Spanish teachers' education courses: syllabuses and curricula developers, teachers and students.
\end{abstract}

Keywords: Applied Linguistics. History. Spanish as a Foreign Language. Textbook. Curriculum. 


\section{Introdução}

A relação entre a língua portuguesa e a língua espanhola tem produzido marcas em ambas, que são altamente produtivas do ponto de vista da pesquisa em ciências humanas- em geral - e, particularmente, nas linguísticas imanente e aplicada. Neste artigo, recorre-se à história para explicar efeitos dessa relação amparada pela proximidade geográfica, pelo compartilhamento de substratos e por uma convivência que deslegitima a consideração desta relação como adstrato ${ }^{1}$.

Nas línguas de grande expansão geográfica - árabe, russo, francês, inglês, espanhol, português, entre outras-, a variante linguística que priva de maior legitimidade como referência mais pertinente nas interações formais é a da escolarização e, por isso, da produção intelectual. Isso decorre da influência política, econômica, militar e cultural do território a partir do qual a língua se expandiu. As metrópoles, nas relações coloniais, privavam dessa influência, mas tão logo começaram os processos independentistas, iniciaram-se também os processos de legitimação das variantes locais. Um exemplo notório é o dos países hispano-falantes da América Latina.

$\mathrm{Na}$ atualidade, a língua espanhola é reconhecida na sua heterogeneidade linguística e cultural pela própria comunidade dos países que a falam como materna. Quando ensinada como estrangeira, porém, ainda emanam inequívocos traços do colonial nas explicações da língua e nas escolhas feitas para apresentar uma referência de adequação modelar.Tomando como contexto o ensino de língua espanhola no Brasil, este trabalho busca subsídios na história para apresentar explicações que contribuam para o seu ensino como língua estrangeira,assimenriquecendoposturas críticas no modo de abordá-la.

\footnotetext{
${ }^{1}$ Cravens, (1994) explica esta tipologia dizendo que substrato é uma lingua que tem menor influência do que outra e um superestrato é uma língua que tem maior influência. Ambos influenciam-se reciprocamente, só que de modo não precisamente equivalente, dependendo dos fatores que imprimem poder a cada um. A categoria adstrato se refere a duas línguas que convivem num mesmo espaço geográfico e temporal, mas sem que se possa estabelecer a maior ou menor influência de cada uma.
} 


\section{Referências históricas}

Na história da Europa a partir da Idade Média tardia -o século XIII-, a relação entre Portugal e Espanha apresentou características que a tornaram singular. Dentre elas, ocupavam lugares de destaque os confrontos bélicos, tratados questionáveis (de Alcaçovas, 1479e de Tordesilhas,1494), a reivindicação da nacionalidade de Cristóvão Colombo (FONTES, s.d.) e o que é mais relevante para o foco deste artigo: a estratégia de preservação do principal patrimônio linguístico local historicamente conhecida como "questão da língua" (SARAIVA, 1995).

Após a morte de dom Sebastião (que não deixou herdeiros), em 1578,o rei espanhol Felipe II, que já havia algum tempo cobiçava o território português, enviou tropas para tomar Portugal à força, consagrando-se, assim, rei de dois reinos. Nas negociações com o poder espanhol, os representantes da elite política, econômica e administrativa portuguesa redigiram um documento, conhecido como o Juramento de Tomar (1581), que tornou possível que a elite portuguesa conservasse muitas prerrogativas nas suas posses coloniais e no próprio território nacional. A invasão espanhola e o pacto dos portugueses materializaram o que passou a ser conhecido como a União Ibérica.

Com a "questão da língua" fazendo parte do Juramento de Tomar, evidencia-se aos olhos dos estudiosos das relações linguísticas na Península Ibérica, que é um território plurilíngue, a atitude portuguesa diante da língua espanhola. A Espanha representava a potência econômica, política e militar a temer. Assim, Portugal não escapava do receio de afetação ou de perda do maior patrimônio identitário coletivo - o da língua vernácula-que, via de regra, é sentido pelos territórios nacionais pequenos ou transformados em periferia, principalmente em ambiente continental ou em espaço geográfico comum. Para apenas fazer menção de um caso que chega aos dias atuais, citamos o exemplo da história da diglossia existente no território belga.

Individualmente e no comportamento dos grupos sociais de maior influência e autoridade, funciona-de modo consciente e 
inconsciente- aquele optimum de permissividade relativamente ao heterogêneo a que Lévi-Strauss $(1986)^{2}$ se referia, explicando o funcionamento da cultura (de que a língua é ponto de partida e de chegada). A partir dessa premissa e dada a inevitável, necessária e intensa dinâmica de intercâmbio entre o português e o espanhol/castelhano (MATO GROSSO, 2010), desenha-se com maior nitidez o caráter árduo do esforço português por uma impermeabilidade linguística e cultural possível em função da própria sobrevivência da nação.

A afirmação anterior parece ganhar tanto mais validade como dado quanto mais filólogos e lexicólogos provam que resulta extremamente difícil estabelecer, em muitos casos, a origem lusa ou espanhola de um número bem significativo de termos e expressões usuais em ambas as línguas (CUESTA, 1981a, ALVAREZ MARTINEZ, 1997). Esseimpasse na atribuição de uma identidade nacional ao léxico reforça o reconhecimento da existência de uma fina trama linguístico-cultural vinculando Espanha e Portugal a ponto de que ícones da literatura portuguesa, para poderem ganhar divulgação no mercado continental, produziam obras em espanhol-Gil Vicente, Sá de Miranda, Luís de Camões, Francisco Manuel de Melo, etc. Esse fato pode ser explicado porque a língua espanhola era uma língua de prestígio e o público leitor na Espanha era numericamente relevante (CUESTA, 1981b; 1986).

A restauração monárquica e independentista em Portugal, processo iniciado em dezembro de 1640, exaltou atitudes nacionalistas e contrárias ao poder espanhol que se refletiram na rejeição à relevância que a língua espanhola tinha alcançado graças à dominação espanhola. A partir de então, essa atitude política se manteve acesa, atravessando a sociedade portuguesa nos níveis consciente e inconsciente, dentro dos muitos limites de uma relação marcada pela

\footnotetext{
2 "Se, como eu já escrevia em "Raça e história", entre as sociedades humanas existe certo optimum de diversidade que elas não ultrapassam, mas aquém do qual também não podem descer sem perigo, deve-se reconhecer que essa diversidade decorre em grande medida, por um lado, do desejo de cada cultura de opor-se às do seu entorno, de distinguir-se delas; numa palavra, de serem elas mesmas. Sem conviverem na mútua ignorância, mas fazendo-se empréstimos umas às outras, para não perecerem, é preciso que uma certa impermeabilidade exista subjazendo entre elas".
} 
dependência lusa e pela cobiça territorial e imperial de uma coroa espanholaem decadência.

O Brasil era a única posse colonial portuguesa que, de certa maneira, reproduzia o conflito linguístico-cultural existente na Península Ibérica, mas de modo exponencialmente maior por causa da enorme extensão das suas fronteiras com territórios hispano-falantes decorrente da imensidão do seu território e porque os inimigos europeus da Espanha -França e Holanda- consideravam o Brasil território espanhol (BERTHELL, 2009).

Paradoxalmente, no caso do território brasileiro, primeiro colônia e depois independente, as reações de autoproteção linguística foram expressivamente favoráveis para os interesses das políticas vernaculistas, já que as caraterísticas das políticas culturais e linguísticas no Brasil funcionaram refletindo a introspecção cultural das classes sociais no poder relativamente à outra parte da América Latina, ao mesmo tempo que possuíam um forte sentimento de singularidade linguística e cultural a respeito de Portugal.

Não houve, por isso, a necessidade de explicitar para os nacionais o funcionamento de uma estratégia de autoproteção cultural e linguística, já que essa veio funcionando naturalmente como se fosse apenas da ordem do inconsciente. Assim, no início, o prevalecente ambiente linguístico de confronto silencioso entre Espanha e Portugal expandiu-se ao território brasileiro e aqui ganhou autonomia potenciada por uma localização geográfica dos principais centros de poder que literalmente dá as costas para o resto do continente com a exceção do Uruguai e da Argentina, também banhados pelo Oceano Atlântico.

\section{Variantes nacionais da língua espanhola e a atribuição de variante de maior prestígio.}

A partir do caráter próprio que a relação dos grupos de poder e das classes letradas herdou do surgimento do Brasil como nação, a visão de língua espanhola deste lado do mundo ganhou referenciais novos decorrentes da pluralidade de países que têm a língua espanhola como língua nacional. Por causa de correntes ideológicas que 
prevaleciam na então colônia -no sentido da busca da independência, concebendo-a como uma reprodução da Europa na América e não como a emergência de uma nova instância política independente da antiga metrópole (BERTHELL, op.cit.) -, a representação de maior circulação no Brasil Império dos novos países independentes na América de fala espanhola não alimentava admiração nem imitações.Pelo contrário, a elite brasileira achava razões, no que acontecia do lado de fala espanhola, para exaltar como positivo o seu próprio comportamento político de transição incruenta para a independência.

Se o projeto de país das classes privilegiadas da ex-colônia partia do princípio de reproduzir o que representavam para si como a Europa no novo continente a partir dos modelos político (a Inglaterra) e cultural (a França), a língua espanhola - na sua variante europeia escolarizada - era a única a ser reproduzida/estudada como língua estrangeira. Porém, assim como eram variadas as realidades sociais e históricas dos novos países de fala espanhola, assim também foi rico o número de variantes nacionais da língua nesta parte do mundo.

Ribeiro (2007) desenvolveu uma tipologia para explicar, num nível macro, a diversidade existente entre os povos latino-americanos. Nela considerou aspectos históricos e etnológicos. Ao recorrer a essas duas referências como ferramentas, prestou um serviço impensado à dialetologia, já que constituindo três grandes grupos de povos (testemunhas, novos e transplantados), a linguagem verbal avalizava a pertinência de tal agrupamento no interior do qual a sociolinguística continua detectando e descrevendo variações ${ }^{3}$.

\footnotetext{
${ }^{3}$ Ribeiro (op. cit.) sustenta que o conjunto de países surgidos de territórios que eram abarcados pelas grandes civilizações pré-colombianas (maias, astecas e incas) apresentam traços antropológicos e etnológicos comuns e a matriz genética indígena é evidente. Esses são classificados por ele como povos testemunhas. Outro conjunto de países se caracteriza pela confluência de matrizes antropológicas e etnológicas indiana, africana e europeia a que denominou povos novos. Por último, um terceiro grande grupo de países -os povos transplantados- tem a sua emergência caracterizada por grandes massas de europeus, num processo de povoamento, que reproduziram em territórios do novo continente o recorte cultural de que eram originários, substituindo por extermínio e/ou marginalização os habitantes históricos ou anteriores e também povoando regiões não habitadas. Para o que chamamos a
} 
À luz das teorias contemporâneas sobre variação linguística (BAGNO, 2000; FAUGHT, 2004), no Brasil, nenhuma das três variações macro é considerada como a mais legítima, implícita ou explicitamente, no momento de fazer uma escolha para introduzir uma variante em currículos que contemplam o ensino de língua espanhola como língua estrangeira. Se na atualidade essa é a postura de maior circulação, na história do ensino da língua, tal privilégio foi monopolizado pela variante ibérica até bem avançado o século XX e, em não poucos imaginários, continua sendo assim por razões que serão referidas a seguir.

\section{Um paradoxo do ensino de língua espanhola no brasil: história e política}

A escolha de uma variante modelar de língua estrangeira a ser ensinada pode se fundamentar em aspectos como: vínculos históricos coloniais ou de subordinação/interdependência político-econômica com um país onde essa língua é materna-, as relações culturais, a proximidade geográfica como propiciadora do fluxo migratório, o efeito de uma política externa eficaz de um país visando penetrar no mercado de um país-alvo ou vice-versa e a busca de influência em vários sentidos num determinado país.

A variante ibérica da língua, considerada como a de maior prestígio durante quase toda a história do ensino da língua espanhola no Brasil, envolve de modo natural as referências à cultura da Espanha (erudita, principalmente, mas também comportamental, o que a vincula com o turístico), encontra justificação na precedência desse país no início do processo de reconfiguração homogeneizadora da maior parte do território que então começava bem ao norte do Rio Bravo.

O esplendor cultural erudito (artístico e literário) da Espanha, promovido pelas elites sociais que essa metrópole ibérica implantou nas colônias, também justifica a escolha como padrão da variante peninsular europeia. Simultaneamente, funcionaram como promotores da preferência pelo padrão europeu os agentes do letramento e da

atenção é para fato de que, em cada um dos três grandes grupos, a linguagem verbal reflete variações relativamente à língua do colonizador. 
ideologia: a escola e a igreja católica, esta última o principal agente ideológico facilitador da implantação da ordem colonial e da prolongação de traços coloniais e/ou dos seus efeitos até à atualidade.

É claro que um elemento da maior importância encontra-se nos milhões de espanhóis, da mais diversa origem social, que desde o final do século XV começaram a se instalar nos territórios coloniais, criando descendência local. Depois da transformação desses territórios em repúblicas independentes até a atualidade, europeus e seus descendentes foram transformados pelas elites e suas instituições em referência de adequação social e de pessoas letradas a serem imitadas ou simplesmente a assim serem consideradas (RAMA, 1985). Consciente ou inconscientemente, as elites latino-americanas não podiam deixar de olhar para a Europa percebendo-a como um todo enquanto metrópole fundadora.

Assim, circunstâncias históricas, os laços (também históricos) que elas criam e efeitos do colonial contribuíram naturalmente para que a variante peninsular da língua espanhola fosse escolhida como a de maior prestigio ao ser introduzida essa disciplina pela primeira vez no currículo escolar brasileiro a partir 1942 em consequência da Lei Orgânica do Ensino Secundário ${ }^{4}$ (CASTELANO, 2010).

A referência justificatória da escolha de um modelo de língua, elencada no início desta subseção, só vai receber o acréscimo de dois fatores que não escoravam a atribuição de relevância à variante peninsular até bem avançada a segunda metade do século passado. São eles: o processo de ampliação do Mercado Comum Europeu e de construção da União Europeia que muito beneficiou a Espanha. Durante vários séculos essa nação, juntamente comPortugal, sul da Itália e Grécia,integrou o grupo de países e regiões subdesenvolvidas produtores de emigrantes da que então era conhecida como a Europa Ocidental.

\footnotetext{
${ }^{4}$ Esse decreto concebido e lançado sob a gestão do Ministro da Saúde e da Educação, Gustavo Capanema, passou a ser referido como a "reforma Capanema", já que significou uma reestruturação da educação no Brasil.
} 


\section{Democracia e auge do ensino da língua na espanha}

O ingresso no Mercado Comum Europeu, em consequência do fím da ditadura franquista ${ }^{5}$, tornou possível a expansão econômica externa do país. Com a abertura ao capital estrangeiro e à circulação de pessoas, a Espanha democratizada transformou-se em importante país de destino do turismo internacional, principalmente norte-europeu. Uniram-se a isso a promoção do país como com condições para transformar-se em lugar de residência de aposentados estrangeiros, além de ser sede de universidades de prestígio para a formação e para o aperfeiçoamento acadêmicos.

Tudo isso teve reflexos no interesse na aprendizagem da língua, o que propiciou a expansão do mercado editorial de livros como as editoras EDELSA, Planeta, Barsa e o Grupo Santillana- para a produção-comercialização de livros didáticos de ensino de espanhol para estrangeiros. Isso impulsionou as pesquisas na didática desse tipo de ensino nas universidades, a formação de professores e o surgimento de autores, aumentando o interesse pelo ensino de espanhol nos contextos europeu e mundial.

A Espanha, assim, tornou-se referência teórica, metodológica e editorial para o ensino de Espanhol como língua estrangeira (doravante E/LE), ofertando cursos de graduação, aperfeiçoamento e pósgraduação e,em consequência disso,contribuindo para reforçar o imaginário da melhor variante da língua a ser ensinada.

\section{0 desestranhamento do espanhol latino-americano}

Neste artigo, tem-se tentado explicitar como o colonial e políticas governamentais têm conseguido preservar o espanhol peninsular no estatuto de variante de preferência na história do ensino da língua no Brasil. É preciso esclarecer, porém, que cada vez mais, dada a maioridade da Linguística Aplicada no mundo e no Brasil, o desenvolvimento dos estudos sociolinguísticos e a vocação pragmática

\footnotetext{
${ }^{5}$ Francisco Franco liderou um governo ditatorial de extrema-direita na Espanha de 1939 a 1975, quando morreu, mas o ultraconservadorismo ainda se prolongou por mais um ano naquele país.
} 
da pós-modernidade, esclarecimentos são introduzidos em livros didáticos produzidos na Espanha e no Brasil a respeito da falta de pertinência de se considerar uma variante da língua melhor do que outras.

Cada vez mais, as variantes latino-americanas deixam de ser apresentadas enquanto exóticas ou curiosas, como até em livros de autoria brasileira apareciam, a exemplo da sessão "Lenguacuriosa" do LD Mucho (ALVES;MELLO, 2001, p. 109) reproduzida no Quadro 1.

Vários fatores têm possibilitado, no Brasil, a afirmação e a legitimação identitária das diversas variantes do espanhol latinoamericano. Isto resulta, em primeiro lugar, do aumento do contato do país, cada vez mais intenso, com a região em decorrência das relações principalmente comerciais, mas também financeiras e políticas, que organismos regionais, a maior parte pré-Mercosul, têm propiciado (ALADI, PARLATINO, SELA, IIRSA, FONPLATA ${ }^{6}$ ). A maior presença de latino-americanos hispano-falantes no território nacional tem crescido em razão do comércio macro e micro empresarial, de convênios acadêmico-culturais e da busca de melhores condições de vida.

A diminuição do estranhamento dos diversos modos como os países vizinhos tornaram sua a língua espanhola tem-se refletido nos programas de formação de profissionais da língua. Num documento oficial como as Orientações Curriculares para o Ensino Fundamental do Estado de Mato Grosso (MATO GROSSO, 2010; p. 64), chama-se a atenção para o fato de que "[...] um dos esforços do professor, por isso, deve estar dirigido a levar os estudantes a compreender que a língua espanhola possui diversas variantes dialetais e que não se pode afirmar que alguma seja a melhor". E acrescenta:

${ }^{6}$ Na mesma ordem: Associação Latino-americana de Integração (1980), Parlamento Latino-americano (1987), Sistema Econômico Latino-americano (1975), Iniciativa para a Integração da Infraestrutura Regional Sul-americana (2000) e o Fundo Financeiro para o Desenvolvimento da Bacia do Prata (1969). 
Quadro 1. Exotizaçãodo léxico em variantes latino-

americanas

\begin{tabular}{|c|c|c|c|c|c|}
\hline \multicolumn{6}{|l|}{ Transportes } \\
\hline España & Argentina & Uruguay & Chile & & México \\
\hline Atasco & $\begin{array}{l}\text { Embotella- } \\
\text { miento }\end{array}$ & $\begin{array}{l}\text { Embotella- } \\
\text { miento }\end{array}$ & Taco & Tranca, cola & $\begin{array}{l}\text { Embotella- } \\
\text { miento }\end{array}$ \\
\hline $\begin{array}{l}\text { Billete de } \\
\text { avión }\end{array}$ & Pasaje, ticket & Pasaje & Pasaje & Pasaje, boleto & Boleto \\
\hline $\begin{array}{l}\text { Billete de ida } \\
\text { y vuelta }\end{array}$ & $\begin{array}{l}\text { Pasaje, ticket } \\
\text { de ida y } \\
\text { vuelta }\end{array}$ & $\begin{array}{l}\text { Pasaje de ida } \\
\text { y vuelta }\end{array}$ & $\begin{array}{l}\text { Pasaje de ida } \\
\text { y vuelta }\end{array}$ & $\begin{array}{l}\text { Pasaje de ida y } \\
\text { vuelta }\end{array}$ & \begin{tabular}{|l} 
Boleto \\
redondo
\end{tabular} \\
\hline $\begin{array}{l}\text { Billete del } \\
\text { metro }\end{array}$ & Boleto & Boleto & Boleto & Ticket & Boleto \\
\hline $\begin{array}{l}\text { Carné o } \\
\text { permiso (para } \\
\text { conducir) }\end{array}$ & $\begin{array}{l}\text { Registro (de } \\
\text { manejar) }\end{array}$ & $\begin{array}{l}\text { Libreta o } \\
\text { licencia (de } \\
\text { conducir) }\end{array}$ & $\begin{array}{l}\text { Carnet de } \\
\text { conducir }\end{array}$ & $\begin{array}{l}\text { Licencia (de } \\
\text { manejar, de } \\
\text { conducir) }\end{array}$ & $\begin{array}{l}\text { Licencia (de } \\
\text { manejar, de } \\
\text { conducir) }\end{array}$ \\
\hline $\begin{array}{ll}\text { Facturar } & \text { el } \\
\text { equipaje }\end{array}$ & $\begin{array}{l}\text { Despachar, } \\
\text { hacer el } \\
\text { check-ln }\end{array}$ & Despachar & $\begin{array}{l}\text { Chequear, } \\
\text { hacer el check- } \\
\text { in }\end{array}$ & $\begin{array}{l}\text { Chequear, } \\
\text {-chequearse }\end{array}$ & $\begin{array}{l}\text { Checar, } \\
\text { registrar }\end{array}$ \\
\hline \begin{tabular}{|l|} 
Gasolinera, \\
estación \\
servicio
\end{tabular} & $\begin{array}{l}\text { Estación de } \\
\text { servicio }\end{array}$ & $\begin{array}{l}\text { Estación de } \\
\text { servicio }\end{array}$ & $\begin{array}{l}\text { Bomba de } \\
\text { bencina, } \\
\text { bencinera, } \\
\text { servicentro }\end{array}$ & $\begin{array}{l}\text { Bomba de } \\
\text { gasolina }\end{array}$ & $\begin{array}{l}\text { Gasolinera, } \\
\text { gasolinería }\end{array}$ \\
\hline Hora punta & Hora pico & Hora pico & $\begin{array}{l}\text { Hora pick, hora } \\
\text { peak }\end{array}$ & Hora pico & Hora pico \\
\hline Llanta & Llanta & Llanta & Llanta & Rin & Rin \\
\hline Matrícula & Patente & $\begin{array}{l}\text { Chapa, placa, } \\
\text { matrícula }\end{array}$ & Patente & Placa & Placa \\
\hline Multa & Boleta, multa & Multa & Parte, multa & Multa & Infracción \\
\hline Neumático & Goma & $\begin{array}{l}\text { Neumático, } \\
\text { cubierta }\end{array}$ & Neumático & Caucho & Llanta \\
\hline $\begin{array}{l}\text { Poner o } \\
\text { echar } \\
\text { gasolina }\end{array}$ & Cargar nafta & $\begin{array}{l}\text { Cargar nafta, } \\
\text { poner nafta }\end{array}$ & Echar bencina & $\begin{array}{l}\text { Poner o } \\
\text { echar } \\
\text { gasolina }\end{array}$ & Cargar gasolina \\
\hline $\begin{array}{l}\text { Remolque } \\
\text { (para carga) }\end{array}$ & Acoplado & $\begin{array}{l}\text { Zorra, } \\
\text { remolque }\end{array}$ & $\begin{array}{l}\text { Remolque (de } \\
\text { coches); } \\
\text { acoplado (de } \\
\text { camiones) }\end{array}$ & Remolque & Remolque \\
\hline $\begin{array}{l}\text { Rueda de } \\
\text { repuesto }\end{array}$ & $\begin{array}{l}\text { Rueda de } \\
\text { auxilio }\end{array}$ & Auxiliar & $\begin{array}{l}\text { Rueda de } \\
\text { repuesto }\end{array}$ & $\begin{array}{l}\text { Caucho de } \\
\text { repuesto }\end{array}$ & $\begin{array}{l}\text { Llanta de } \\
\text { refacción }\end{array}$ \\
\hline $\begin{array}{l}\text { Tener una } \\
\text { rueda pinchada }\end{array}$ & $\begin{array}{l}\text { Tener una } \\
\text { goma } \\
\text { pinchada }\end{array}$ & $\begin{array}{l}\text { Tener una } \\
\text { rueda } \\
\text { pinchada }\end{array}$ & $\begin{array}{l}\text { Tener un } \\
\text { neumático } \\
\text { pinchado }\end{array}$ & $\begin{array}{l}\text { Tener un } \\
\text { caucho } \\
\text { espichado }\end{array}$ & $\begin{array}{l}\text { Tener una } \\
\text { llanta } \\
\text { ponchada }\end{array}$ \\
\hline
\end{tabular}


Dadas as peculiaridades da língua espanhola em cada país, é importante evitar que, no processo didático, a língua se transforme numa mistura eclética de léxico e fonética que não a identifique com nenhuma dessas variantes. Nesse caso, estaríamos fabricando uma língua fictícia porque o que caracteriza o ensino de línguas estrangeiras é que essas línguas são naturais, com falantes reais que organizam o pensamento, se comportam de uma certa maneira $e$ explicam o mundo a partir de uma plataforma básica comum. Explicitar aspectos dessa plataforma é tarefa do professor. (p. 64)

Contudo, ainda se mantém em latência a referência ao espanhol europeu como modelo de maior pertinência para o ensino da língua nas mentes de profissionais brasileiros responsáveis pela sua inclusão como disciplina curricular no ensino público. Essa é uma conclusão a que se pode chegar a partir do pronunciamento da Associação de Professores de Espanhol do Estado de São Paulo (Apeesp, 2011) sobre a proposta curricular de língua espanhola para o ensino médio naquele estado como parte das Orientações Curriculares locais.

A Apeesp apresenta várias críticas e sugestões de retificação do documento. Assim, na direção que mais interessa para este trabalho, a associação expressa:

No entanto, e tendo em vista as próprias características assumidas pelo documento (flexível, aberto e dinâmico), gostaríamos de comentar alguns pontos que consideramos questionáveis ou que podem gerar mal entendidos:

b) A inserção do "Marco comúneuropeo de referencia" na bibliografia, sendo que, além de não ser citado no texto, não diz respeito ao Ensino de Espanhol como Língua Estrangeira Moderna no currículo da Educação Básica no Brasil.

E continua no item "d":

d) A falta de menção/reconhecimento da historicidade comum entre o Brasil e os países hispano-falantes, com os quais configura a América Latina. No documento, resumese tal relação a uma situação conjuntural (p. 2, 16), 
enquanto se estabelece uma relação com as "raizes ibéricas", para justificar a presença do Espanhol no currículo (p. 2), sendo que tais raízes no Brasil têm a ver com Portugal. Para servir como justificativa, as raízes ibéricas fazem sentido se considerada a América Latina como um todo. Além disso, emprega-se "país com fortes raizes ibéricas e vocação cosmopolita" (p.16) como aposto de Brasil, o que é no mínimo uma visão muito parcial.

Entre os fatores afirmativos das variedades latino-americanas de língua espanhola, há dois que se apresentam como os mais importantes: a constituição do Mercosul em 1991 e a Lei no . 11.161 de 2005, que estabelece a oferta obrigatória da disciplina Língua Espanhola no ensino médio. O primeiro dos fatores constituiu a molamestra do estreitamento comercial e financeiro dos quatro países fundadores (Argentina, Brasil, Paraguai e Uruguai) a que se acrescentou recentemente a Venezuela. No documento do acordo, explicita-se que as línguas oficiais são o espanhol, o português e o guarani, o que representa que, para os efeitos do Brasil- o único dos quatro que não possui a língua espanhola como oficial- estava estabelecida a necessidade de o país assumir uma política pública a respeito do espanhol, como veio a acontecer quatro anos depois por meioda lei referida neste parágrafo.

Foi na rede particular de institutos de idiomas e nos centros de línguas de universidades nos quais o ensino de E/LE teve sua existência mais expressiva antes da oficialização da necessidade de incluí-la como oferta nos currículos do ensino médio. Em verdade, a rede particular de ensino de idiomas protagonizou algo que marcou o início do processo de desestranhamento do espanhol latino-americano. Trata-se de que a maioria dos professores disponíveis de língua espanhola não possuíam formação na área. Em muitos casos, eram falantes nativos hispano-americanos que eram professores e/ou profissionais de outras áreas.

Diante da apresentação do espanhol ibérico como língua modelo nos livros didáticos, espontaneamente os professores falantes naturais da língua começavam um processo de explicitação para os estudantes da necessidade de relativizar aspectos normativos que os livros didáticos de autoria espanhola sustentavam, mostrando assim um horizonte linguístico maior para a língua em uso. 


\section{O LD de E/LE}

Os livros didáticos de produção espanhola, apesar de explicitarem a validade das variantes latino-americanas, nem por isso deixa(va)m de ilustrar os usos no continente americano com laivos de exotismo. Isso materializa-se quando as peculiaridades americanas são referidas e ilustradas, sem maiores explicações anteriores ou posteriores, e segue adiante, porque se tratou de uma curiosidade. Pode-se constatar isso nas páginas 88 e 164 do Livro de exercícios e do Livro do aluno do LD Ven 1(CASTRO et alii, 1998) reproduzidas no Quadro 2.

Quadro 2: Exotização do léxico e de aspectos sintáticos no LD Ven

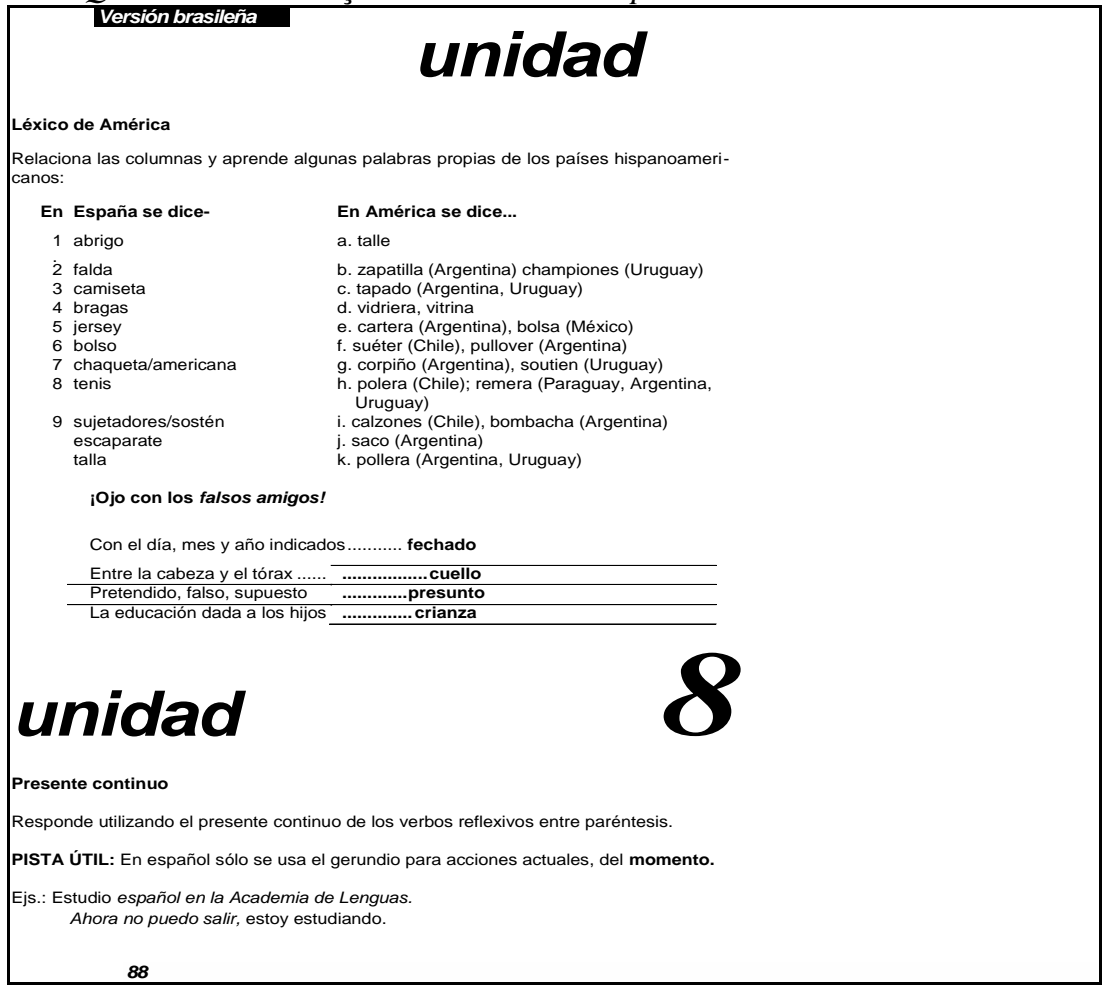


Quadro 2 - cont.: Exotização do léxico

e de aspectos sintáticos no $L D$ Ven

- HAY QUE + verbo en Infinitivo

Es una forma invariable que significa "es necesario".

Formas diferentes de expresar la condición.

si + Presente de Indicativo, verbo en Presente

Si tienes tiempo, vamos esta tarde al cine

$\mathrm{si}+$ Presente de Indicativo, verbo en Futuro

Si tienes tiempo, iremos esta tarde al cine

$\mathrm{si}+$ Presente de Indicativo, verbo en Imperativo

Si tienes tiempo, ven al cine conmigo

Comparaciones: (II)

bueno $(+) \rightarrow$ mejor $(++)$

malo $(-) \rightarrow$ peor $(------)$

Esta moto es peor que aquella.

Juan canta mejor que yo.

\section{UNDAD 14}$$
\text { canta mejor que yo. }
$$

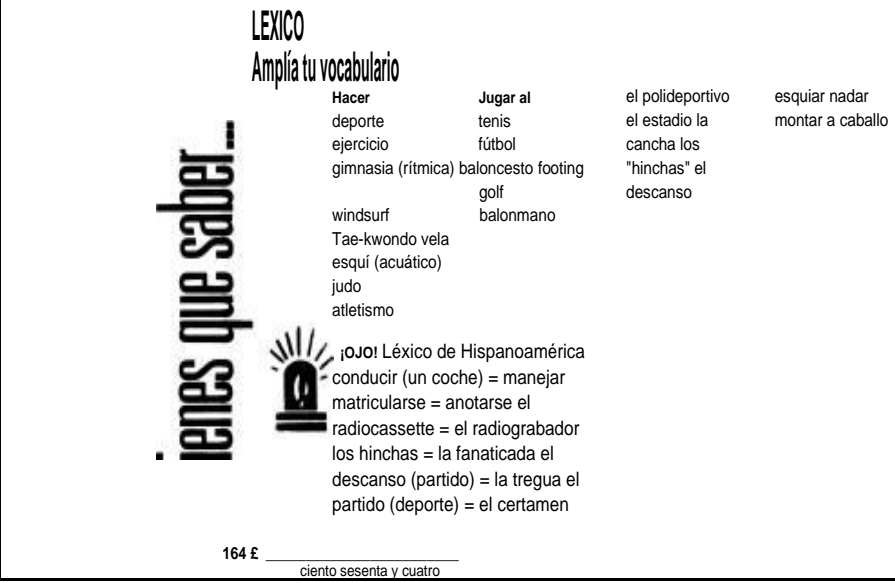

Uma referência que reforça o que tem sido sustentado sobre a prevalência da variante ibérica pode-se ler no prólogo desse título no livro de exercícios da "versión brasileña":

No obstante, la unidad de la lengua entre los hispanohablantes escolarizados es muy grande [...], la mayoría de los materiales didácticos se vuelca hacia la variante centro norte de España. Por eso VEN, que innovó al prestarle atención al idioma en América, [...] pretende [...] dar noticia más detallada de sus variantes (p.II). 


\section{Considerações finais}

Um fator afirmativo irreversível que releva o valor pragmático da valorização da língua espanhola na América Latina para o Brasil consiste no aumento exponencial de cursos de formação de professores de E/LE como licenciatura ou como habilitação nas universidades e o número cada vez maior de professores com pós-graduação stricto sensu nos níveis de mestrado e doutorado em cursos superiores brasileiros, o que contribui de modo definitivo para construir e/ou aprimorar posturas dos profissionais em sintonia com a produção científica contemporânea e cujo resultado, já há alguns anos, começou a se fazer perceber no mercado por meio do lançamento regular de livros didáticos de E/LE de autores brasileiros, destinados para $o$ público brasileiro ${ }^{7}$.

Assim, em consonância com o modo como foram apresentados fundamentos para a escolha de uma variante modelo do idioma, podemos concluir esta perspectiva histórica, esclarecendo que, como é regra nas línguas que se expandiram por grandes espaços geográficos, não é conveniente, em função das capacidades que se busca construir no aprendiz estrangeiro, que ele seja excluído do conhecimento da prevalência da diversidade na aparente homogeneidade das línguas. Elas refletem aspectos identitários fundamentais coletivos e individuais como o modo de organizar uma visão de mundo, que justifica o comportamento nele e se materializa nas práticas sociais.

A pedagogização das línguas processa-se a partir da padronização, e a escola a institui, tendo como referência a sua principal ferramenta de trabalho: a escrita. A língua materna é o exemplo mais acabado disso. As línguas estrangeiras, por sua parte, são apresentadas funcionando principalmente na oralidade, mas o seu planejamento didático acontece cuidando de preservar a lógica a que as normas do uso formal obrigam. Essas têm respaldo na escrita por meioda gramática. O ensino de línguas apresenta como modelo de uso

\footnotetext{
${ }^{7}$ Até a década de noventa, era comum aparecer estampado na capa dos livros didáticos de E/LE de autores espanhóis o dizer "Edición brasileña" sem nenhuma mudança no corpo do livro que justificasse isso (Flores, 2003, p. 91).
} 
a variante letrada, a dos grupos sociais escolarizados, o que busca a homogeneização e alimenta o imaginário do homogêneo no público. Isso não é reversível nem justifica que possa ser diferente no contexto institucional da escola.

No caso da língua espanhola, como efeito do fluxo migratório, da proximidade geográfica e da política oficial de aproximação dos países vizinhos por necessidades comerciais e políticas, não se trata de que se recuse a existência de uma variante modelo do idioma nos LD brasileiros, mas de que se saliente a necessidade de reconhecer que, dadas as circunstâncias explicitadas até aqui, a partir da segunda metade do século $\mathrm{XX}$, tem sido cada vez mais imperativa a necessidade da inclusão da presença de variantes latino-americanas nos LDs. As condições políticas, comerciais, acadêmicas, pedagógicas e sociais têm possibilitado que o estudante brasileiro tenha contato com uma representação da língua espanhola em maior sintonia com esta parte do mundo a que ele pertence e, por isso, com as suas necessidades.

\section{Referências}

ALVAREZ MARTÍNEZ, Maria Angeles. El español y el português: aspectos léxicos.Cuadernos Hispanoamericanos, v. 570, dez. 1997. Disponível em:

http://dialnet.unirioja.es/servlet/listaarticulos?tipo_busqueda=EJEMPL AR\&revista_busqueda $=387 \&$ clave_busqueda $=16234$. Acesso em: 12 jul. 2012.

ALVES, Adda N. M.; MELO, Angelica. Mucho (2): español para brasileños. 2. ed. São Paulo: Moderna, 2001.

APEESP . Pronunciamento. 15/02/2001. Disponível em:

<http://www.apeesp.com.br/web/?p=1113 > . Acesso em: 01 ago. 2012.

BAGNO, Marcos. Preconceito linguístico: o que é, como se faz. 3. ed. São Paulo: Edições Loyola, 2000. 
A relação da língua portuguesa com a língua espanhola...

BETHELL, Leslie. O Brasil e a ideia de "América Latina" em perspectiva histórica. Trad. Érica Cristina de Almeida Alves. Estudos Históricos, v.22, n.44, Rio de Janeiro, 2009.

CASTRO, Francisca et alii. Ven: libro del profesor. Nivel elemental. Madri: Edelsa, Grupo Didascalia, 1995.

CRAVENS, Theodor. Substratum. The encyclopedia of language and linguistics. v. 1. Oxford: Pergamon Press, 1994. p. 4396-4398.

CUESTA, Pilar V. V. Gramática portuguesa. Madri: Gredos, 1981a.

O bilinguismo castelhano-português na época de Camões. Separata dos arquivos do Centro Cultural Português. Paris: Fundação Calouste Gulbenkian, 1981b.

A língua e a cultura portuguesas no tempo dos Filipes. Lisboa: Publicações Europa-América, 1986.

FONTES, Carlos. Lusotopia. Disponível em: http://lusotopia.no.sapo.pt/ Acesso em: 27 jun. 2012.

FOUGHT, Carmen. (Ed.). Sociolinguistic variation: critical survey. New York: Oxford University Press, 2004.

LÉVI-STRAUSS,Claude. O olhar distanciado. Lisboa: Ed. 70, 1986.

MATO GROSSO. Orientações curriculares para o ensino fundamental do estado de Mato Grosso. Livro Linguagens. Cuiabá: SECRETARIA de Estado da Educação. 2010.

PEDROSO, Sergio F. Literatura e tradução no ensino de espanhol língua estrangeira. 271 p. Tese (Doutorado em Linguística Aplicada) Instituto de Estudos da Linguagem, Unicamp, Campinas, 2003.

RAMA, Ange. A cidade das letras. Trad. Emir Sader. São Paulo: Brasiliense, 1985. 
RIBEIRO, Darcy. As Américas e a civilização: processo de formação e causas do desenvolvimento desigual dois povos americanos. São Paulo: Companhia das Letras, 2007.

RODRIGUES, Fernanda S. C. Língua viva, letra morta: obrigatoriedade e ensino de espanhol no arquivo jurídico e legislativo brasileiro. 342 p. Tese (Doutorado em Letras) - Faculdade de Filosofia, Letras e Ciências Humanas, USP, São Paulo, 2010. Disponível em: http://www.teses.usp.br/teses/disponiveis/8/8145/tde07072010-

162106/publico/Tese Fernanda S Castelano Rodrigues.pdf. Acesso em: 27 jun. 2012.

SARAIVA, José Hermano. História concisa de Portugal. 17. ed. Lisboa: Publicações Europa-América, 1995.

Submetido em: 04/05/2013 Aceito em: 01/09/2014

Title: The relationship between Portuguese and (Peninsular and Latin American) Spanish: reflections on textbooks 